\title{
Thyroid function, as assessed by TSH, and future risk of venous thromboembolism: the Tromsø study
}

\author{
Gunhild Lerstad ${ }^{1,2}$, Kristin F Enga ${ }^{2}$, Rolf Jorde ${ }^{3,4}$, Ellen E Brodin ${ }^{1,2,4}$, \\ Johan Svartberg ${ }^{3,4}$, Sigrid K Brækkan ${ }^{1,2,4}$ and John-Bjarne Hansen 1,2,4 \\ ${ }^{1}$ Department of Clinical Medicine, K.G. Jebsen Thrombosis Research and Expertise Center (TREC), \\ ${ }^{2}$ Hematological Research Group (HERG), Department of Clinical Medicine and ${ }^{3}$ Endocrine Research Group, \\ Department of Clinical Medicine, University of Tromsø, N-9037 Tromsø, Norway and \\ ${ }^{4}$ Division of Internal Medicine, University Hospital of North Norway, Tromsø, Norway
}

\author{
Correspondence \\ should be addressed \\ to G Lerstad \\ Email \\ gunhild.lerstad@uit.no
}

\section{Abstract}

Objective: The relationship between thyroid function and the risk of venous thromboembolism (VTE) has not been addressed in population-based cohorts. We investigated the association between TSH levels and the risk of VTE in a general adult population. Design: Population-based cohort study.

Methods: TSH was measured in 11962 subjects aged 25-89 years who participated in Tromsø 4-6 starting in 1994-1995. Incident VTE events were recorded through 31st December 2010. Cox's regression models with TSH as a time-varying covariate were used to calculate hazard ratios (HRs) of VTE by TSH categories (low TSH: $<0.05 \mathrm{mU} / \mathrm{l}$; moderately reduced TSH: $0.05-0.19 \mathrm{mU} / \mathrm{l}$; normal TSH: 0.20-4.00 mU/l; moderately elevated TSH: 4.01-5.00 mU/l; and high TSH: > 5.00 mU/l) and within the normal range of TSH, modeling TSH as a continuous variable.

Results: There were 289 VTEs during 8.2 years of median follow-up. Subjects with low (prevalence: $0.22 \%$ ) and high (3.01\%) TSH had slightly higher risk estimates for VTE than did subjects with normal TSH (multivariable HRs: 2.16, 95\% CI 0.69-6.76 and 1.55, 95\% Cl 0.87-2.77 respectively), but the Cls were wide. Moreover, there was no association between TSH within the normal range and VTE (HR per $1 \mathrm{mU} / \mathrm{l}$ increase: $0.95,95 \% \mathrm{Cl} 0.82-1.11$ ).

Conclusion: Serum levels of TSH within the normal range were not associated with a risk of VTE, whereas low and high TSH levels were rare and associated with a moderately higher risk of VTE. The present findings suggest that only a minor proportion of the VTE risk in the population can be attributed to thyroid dysfunction.

\section{Introduction}

The prevalence of thyroid disorders is markedly increasing in the general population, and the world faces a burden of thyroid disease that has reached epidemic proportions $(1,2)$. Thyroid hormones are the main regulators of metabolism, and the thyroid-stimulating hormone (TSH) is generally considered to be the most sensitive measure of thyroid function (http://www.endocrine.niddk.nih.gov/ pubs/thyroidtests/, accessed 12th April 2013).

A hypercoagulable state has been linked to both hyperthyroidism $(3,4,5,6)$ and subclinical, as well as overt, moderate hypothyroidism $(7,8,9,10)$. A relationship has also been reported between thyroid dysfunction and arterial cardiovascular diseases (CVDs) $(11,12)$.

Venous thromboembolism (VTE) is a collective term for deep vein thrombosis (DVT) and pulmonary embolism (PE). It is the third most common CVD (13), and it is associated with severe short- and long-term complications and a potentially fatal outcome $(14,15)$. Even though many acquired and genetic risk factors have been associated with VTE $(13,14,15,16,17), 30-50 \%$ of the (c) 2015 European Society of Endocrinology Printed in Great Britain
Published by Bioscientifica Ltd. 
events still have no obvious provoking factors $(18,19,20)$. The identification of biomarkers and risk behaviors of VTE that could be subject to modification is important to reduce the disease burden.

The impact of thyroid function on VTE risk has not been extensively examined. A recent case-control study (21) and a population-based nested case-cohort study (22) reported that high levels of free thyroxine $\left(\mathrm{FT}_{4}\right)$ were associated with an increased risk of VTE. Conversely, TSH levels were inversely associated with VTE risk, but the relationship was attenuated as compared to $\mathrm{FT}_{4}$. The casecontrol study (21) was limited to a population with suspected DVT, and because of the retrospective design, the levels of $\mathrm{FT}_{4}$ could potentially have been influenced by the thrombotic event itself. In the nested case-cohort study (22), blood was sampled only once, and because thyroid parameters are modifiable, changes in these parameters during follow-up may have affected the risk estimates.

Limited data exist on the association between TSH and a risk of VTE at the population level, particularly in terms of population-attributable risks, so the aim of the present cohort study was to examine the association between thyroid function, as assessed by TSH, and future risk of VTE in a general adult population with repeated measures of TSH.

\section{Subjects and methods}

\section{Study population}

Participants were recruited from the fourth, fifth, and sixth survey of the Tromsø study (conducted in 1994-1995, 2001-2002, and 2007-2008 respectively) (23). In addition to these survey members, part of the population aged $\geq 25$ years living in the municipality of Tromsø, Norway, were invited to participate. The overall attendance rate was high, ranging from $66 \%$ in Tromsø 6 to $78 \%$ in Tromsø 4. A total of 12959 individuals aged 25-89 years participated in at least one survey, and of these, 3035 participated in two or more surveys. A detailed description of the study participation has been published elsewhere (23). Subjects who did not consent to medical research $(n=225)$, subjects who were not officially registered as inhabitants of the municipality of Tromsø at baseline $(n=18)$, and subjects with a known prebaseline history of VTE $(n=85)$ were excluded from the study. Furthermore, subjects were excluded if they had missing TSH values in all visits $(n=891)$. In total, 11962 subjects were included in the study (Fig. 1) and followed from the date of enrollment through the end of the study

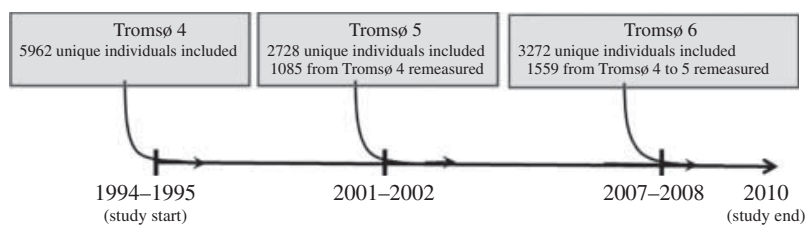

\section{Figure 1}

Presentation of subjects included from the different Tromsø visits (1994-1995, 2001-2002, and 2007-2008). There were 3035 subjects who participated in two or three surveys.

period on 31st December 2010. The study was approved by the regional committee of medical and health research ethics, and all participants gave their informed written consent to participate.

\section{Measurements}

Baseline information was collected by physical examinations, blood samples, and self-administered questionnaires (24). Information on the history of CVD (i.e., angina pectoris, myocardial infarction (MI), and stroke), current daily smoking, and physical activity ( $\geq 1 \mathrm{~h}$ /week) during leisure time was collected from the qustionnaires. Height and weight were measured, and BMI was calculated as weight in kilograms divided by the square of height in meters $\left(\mathrm{kg} / \mathrm{m}^{2}\right)$. Non-fasting blood samples were collected from an antecubital vein, and serum was prepared by centrifugation after $1 \mathrm{~h}$ respite at room temperature and further analyzed at the Department of Clinical Chemistry, University Hospital of North Norway. Serum samples were analyzed for TSH with the AxSYM instrument (Abbott) and stored frozen at $-70^{\circ} \mathrm{C}$. In our laboratory, the reference range for serum TSH was 0.20 $4.00 \mathrm{mU} / \mathrm{l}$. Serum total cholesterol and triglycerides were analyzed by enzymatic colorimetric methods and commercially available kits (CHOD-PAP for cholesterol and GPOPAP for triglycerides; Boehringer-Mannheim, Mannheim, Germany). Serum HDL cholesterol was measured after the precipitation of LDLs with heparin and manganese chloride.

\section{VTE ascertainment}

All first-lifetime events of VTE among the participants during follow-up were recorded from the date of enrollment to the end of the study period, as previously described in detail (25). Based on the presence of provoking factors at the time of diagnosis, the VTE event 
was classified as either unprovoked (no provoking factors) or provoked (greater than or equal to one provoking factor(s)). Major surgery, trauma, or an acute medical condition (such as acute MI, ischemic stroke, or major infectious disease) $(26,27)$ within 8 weeks before the event, active cancer at the time of the event, and marked immobilization (e.g., bed rest for $\geq 3$ days, wheelchair use $(28,29)$, or long-distance travels of $\geq 4 \mathrm{~h}$ within 14 days before the event) were considered provoking factors.

\section{Statistical analysis}

The date of study enrollment for each individual was determined as the date of attendance in the first survey in which TSH measurements were available (Fig. 1). Personyears were accrued from the date of enrollment through the date when a VTE event was first diagnosed, the date of migration or death, or the end of the study period (31st December 2010), whichever came first. We used a timevarying analysis that allowed participants $(n=1559)$ who were remeasured in Tromsø 5 and Tromsø 6 to change (update) levels of TSH over time. Thus, 11962 individuals contributed, and there were 18276 observational periods.

Statistical analyses and power calculations were carried out using STATA version 12.0 (Stata Corp., College Station, TX, USA). The significance level was 0.05 . Population attributable risk fraction (PAR\%), the share of events among the general population that can be explained by thyroid dysfunction (i.e., TSH levels of $<0.02$ or $>4 \mathrm{mU} / \mathrm{l}$ ), was calculated from incidence rates (IRs) of VTE in the general population (Ip) and in the population with euthyroid subjects $(\mathrm{Io})(\mathrm{PAR} \%=((\mathrm{Ip}-\mathrm{Io}) / \mathrm{Ip}) \times 100 \%)$.
Cox-proportional hazards regression models, with levels of TSH and potential confounders entered as time-varying covariates, were used to estimate hazard ratios (HRs) with 95\% CIs for VTE by increasing levels of TSH. Age was used as time-scale, and the subject's age at study enrollment was defined as entry time, whereas exit time was defined as age at date of VTE diagnosis, migration, death, or study end. HRs for all VTE events, as well as for DVT and PE and for provoked and unprovoked VTE, were estimated in sexand multivariable-adjusted analyses. In the multivariate model, we adjusted for sex, BMI, and smoking. HRs of VTE according to predefined categories of TSH (low TSH: $<0.05 \mathrm{mU} / \mathrm{l}$; moderately reduced TSH: $0.05-0.19 \mathrm{mU} / \mathrm{l}$; normal TSH: $0.20-4.00 \mathrm{mU} / \mathrm{l}$; moderately elevated TSH: 4.01-5.00 mU/l; and high TSH: $>5.00 \mathrm{mU} / \mathrm{l}$ ) were calculated, and subjects with normal TSH were used as the reference category. Moreover, to investigate whether there was any gradient of VTE risk within the normal range of TSH, we calculated the HR per $1 \mathrm{mU} / \mathrm{l}$ increase in TSH in analyses restricted to those with normal levels $(0.20-4.00 \mathrm{mU} / \mathrm{l})$. Potential interactions with sex were tested for all risk factors. The proportional hazard assumption was verified by evaluating the parallelism between the curves of the log-log survivor function for different categories of TSH.

\section{Results}

Baseline characteristics of participants according to categories of TSH are shown in Table 1 . The prevalence of low TSH, moderately reduced TSH, moderately elevated $\mathrm{TSH}$, and high TSH was $0.22,1.06,3.01$, and $2.58 \%$

Table 1 Clinical characteristics across categories of thyroid-stimulating hormone (TSH). The Tromsø study, 1994-2010. Values are means \pm s.D. or percentages (numbers).

\begin{tabular}{|c|c|c|c|c|c|}
\hline & \multicolumn{5}{|c|}{ TSH (mU/l) } \\
\hline & Low $(<0.05)$ & $\begin{array}{c}\text { Moderately reduced } \\
\quad(0.05-0.19)\end{array}$ & Normal $(0.20-4.00)$ & $\begin{array}{c}\text { Moderately elevated } \\
\quad(4.01-5.00)\end{array}$ & High $(\geq 5.00)$ \\
\hline Exposure periods (\%) & $0.22(41)$ & $1.06(194)$ & $93.1(17020)$ & $3.01(550)$ & $2.58(471)$ \\
\hline Age (years) & $62 \pm 8$ & $65 \pm 10$ & $61 \pm 12$ & $66 \pm 10$ & $65 \pm 10$ \\
\hline Sex (\% women) & $75.6(31)$ & $82.5(160)$ & $56.3(9577)$ & $53.8(296)$ & $53.1(250)$ \\
\hline $\mathrm{BMI}$ & $27.35 \pm 4.92$ & $27.35 \pm 4.61$ & $26.64 \pm 4.20$ & $27.29 \pm 4.43$ & $27.00 \pm 4.29$ \\
\hline Systolic blood pressure & $148 \pm 26$ & $142 \pm 23$ & $140 \pm 23$ & $144 \pm 23$ & $144 \pm 24$ \\
\hline Diastolic blood pressure & $83 \pm 15$ & $78 \pm 11$ & $80 \pm 12$ & $80 \pm 12$ & $81 \pm 12$ \\
\hline Triglycerides & $1.67 \pm 0.70$ & $1.55 \pm 0.89$ & $1.56 \pm 0.93$ & $1.63 \pm 1.00$ & $1.59 \pm 0.83$ \\
\hline Total cholesterol & $6.23 \pm 1.27$ & $5.90 \pm 1.16$ & $6.11 \pm 1.22$ & $6.11 \pm 1.25$ & $6.17 \pm 1.30$ \\
\hline HDL cholesterol & $1.50 \pm 0.42$ & $1.55 \pm 0.40$ & $1.52 \pm 0.43$ & $1.49 \pm 0.46$ & $1.51 \pm 0.44$ \\
\hline Smoking (\%) & $24.4(10)$ & $19.9(38)$ & $26.1(4410)$ & $12.3(67)$ & $17.8(82)$ \\
\hline Physical activity (\%) & $17.1(7)$ & $49.5(50)$ & $45.7(5262)$ & $50.3(165)$ & $45.1(124)$ \\
\hline Cardiovascular disease $^{a}$ & $9.8(4)$ & $14.9(28)$ & $13.1(2186)$ & $17.9(97)$ & $18.2(84)$ \\
\hline
\end{tabular}

${ }^{\mathrm{a}}$ History of myocardial infarction, angina pectoris, or stroke. 
Table 2 Characteristics of VTE patients $(n=289)$ at the time of VTE diagnosis. The Tromsø study, 1994-2010. Values are percentages with numbers in brackets.

\begin{tabular}{|c|c|c|}
\hline & $\begin{array}{l}\text { Deep vein } \\
\text { thrombosis }\end{array}$ & $\begin{array}{l}\text { Pulmonary } \\
\text { embolism }\end{array}$ \\
\hline Percentage $(n)$ & 56.7 (164) & $43.3(125)$ \\
\hline Unprovoked $^{\mathrm{a}}$ & $34.7(57)$ & $45.6(57)$ \\
\hline \multicolumn{3}{|l|}{ Clinical risk factors } \\
\hline Estrogens ${ }^{\mathrm{b}}$ & $6.8(12)$ & $1.3(2)$ \\
\hline Heredityc & $2.5(4)$ & $1.6(2)$ \\
\hline Pregnancy/postpartum & $1(0.6)$ & $0(0)$ \\
\hline Other medical conditions ${ }^{d}$ & $17.7(29)$ & $34.4(43)$ \\
\hline \multicolumn{3}{|l|}{ Provoking factors } \\
\hline Surgery & $17.1(28)$ & $16.0(20)$ \\
\hline Trauma & $8.5(14)$ & $4.8(6)$ \\
\hline Acute medical conditions & $12.8(21)$ & $19.2(24)$ \\
\hline Cancer & $26.8(44)$ & $24.8(31)$ \\
\hline $\begin{array}{l}\text { Immobilization (bed rest } \\
>3 \text { days, wheelchair) }\end{array}$ & $26.8(44)$ & $16(12.8)$ \\
\hline Other ${ }^{\mathrm{e}}$ & $6.7(11)$ & $3.2(4)$ \\
\hline
\end{tabular}

VTE, venous thromboembolism.

aNo provoking factors at the time of diagnosis.

${ }^{b}$ Hormone replacement therapy/oral contraceptives.

${ }^{c}$ Family history of VTE in first-degree relative before the age of 60 years.

${ }^{\mathrm{d} O t h e r}$ diseases within the previous year (myocardial infarction, ischemic stroke, heart failure, inflammatory bowel disease, chronic infection, chronic obstructive pulmonary disease, or myeloproliferative disorder).

eOther factor specifically described as provoking in the medical record (e.g., intravascular catheter).

respectively. The proportion with elevated TSH levels $(>4.00 \mathrm{mU} / \mathrm{l})$ and lowered TSH levels $(<0.20 \mathrm{mU} / \mathrm{l})$ was 5.6 and $1.3 \%$ respectively. Subjects with TSH values outside of the normal reference range $(0.20-4.00 \mathrm{mU} / \mathrm{l})$ were older, had slightly higher BMI and systolic blood pressure, and were more likely non-smokers. Furthermore, subjects with TSH below $0.20 \mathrm{mU} / 1$ were more frequently women, and in subjects with TSH below $0.05 \mathrm{mU} / \mathrm{l}$, the proportion of people who performed regular physical activity was markedly decreased (Table 1).

There were 289 validated incident VTE events during a total of 97672 person-years of follow-up. The median time from TSH measurement to the end of each follow-up period was 6.0 years (range 0.01-16.3). The overall crude IR of VTE was 2.9/1000 person-years (95\% CI 2.62-3.30). The characteristics of VTE patients at the time of the event are shown in Table 2. Among the subjects with incident VTE, 56.7\% had DVT and 43.3\% had PE (Table 2). Moreover, 114 events (39.4\%) were classified as unprovoked. Cancer was the most common provoking factor (26.0\% of the VTE patients had a cancer-related VTE), followed by immobilization (20.7\%) (Table 2).

In the categorized analyses adjusted for sex (Table 3), subjects within the lowest and highest TSH categories
( $<0.05$ and $>5.00 \mathrm{mU} / \mathrm{l}$ respectively) had a $2.3-$ and a 1.5-fold higher risk of VTE as compared to those who had TSH values within the normal reference range (HRs: 2.30, 95\% CI 0.73-7.18 and 1.46, 95\% CI 0.82-2.61 respectively). Further adjustments for BMI and smoking altered the risk estimates slightly (multivariable HRs: 2.16, 95\% CI 0.69-6.76 and 1.55, 95\% CI 0.87-2.77, for the lowest and highest categories respectively). The HR of VTE in subjects with moderately elevated TSH (4.01$5.00 \mathrm{mU} / \mathrm{l})$ vs those with normal TSH was 1.32 (95\% CI 0.75-2.31), whereas the corresponding HR in moderately reduced TSH (0.05-0.19 mU/1) was 0.73 (95\% CI 0.18 2.95). Of note, the number of events in the lower and higher TSH categories was low, and all of the CIs were wide. There was no association between TSH and a risk of VTE when the analyses were restricted to subjects with TSH levels within the normal range (Fig. 2) and the HR per $1 \mathrm{mU} / 1$ increase in TSH was 0.95 (95\% CI 0.82-1.11).

In subgroup analyses (Table 3), the risk estimates for the lowest and highest categories of TSH were higher for provoked VTE (multivariable HRs: 2.51, 95\% CI $0.62-$ 10.19 and $1.99,95 \%$ CI $1.01-3.90$ respectively) than they were for unprovoked VTE (multivariable HRs: 1.66, 95\% CI 0.23-11.99 and 0.94, 95\% CI 0.30-2.97 respectively), but the CIs were wide and overlapping. Moreover, the risk estimates for DVT by the lowest and highest TSH categories were higher (multivariable HRs: 2.72, 95\% CI $0.67-11.0$ and $1.70,95 \%$ CI $0.80-3.65$ respectively) than they were for PE (multivariable HRs: 1.52, 95\% CI $0.21-$ 11.0 and $1.37,95 \%$ CI 0.56-3.37 respectively) as compared to euthyroid subjects, although these results were not statistically significant.

Finally, we merged the lower and upper categories of TSH in order to estimate the proportion of VTEs in the population that could be attributed to thyroid dysfunction. The overall PAR\% for VTE by thyroid dysfunction was $4.4 \%$ (95\% CI 1.0-9.1\%). In separate analyses of provoked and unprovoked VTE, subjects with thyroid dysfunction had a 1.7-fold higher risk of provoked VTE (multivariable HR: 1.67, 95\% CI 1.06-2.64) as compared to euthyroid subjects. No association was found between thyroid dysfunction and unprovoked VTE (multivariable HR: 0.98, 95\% CI 0.50-1.95). In separate analyses with DVT and PE as outcomes of interest, subjects with thyroid dysfunction had a 1.6-fold higher risk of DVT (multivariable HR: 1.57, 95\% CI 0.96-2.58), whereas there was no apparent association with PE (multivariable HR: 1.17, 95\% CI 0.27-1.38) (data not shown). 
Table 3 Incidence rates (IR) and hazard ratios (HRs) with $95 \%$ Cls for venous thromboembolism (VTE) according to categories of thyroid-stimulating hormone (TSH).

\begin{tabular}{|c|c|c|c|c|c|}
\hline & \multicolumn{5}{|c|}{ TSH (mU/l) } \\
\hline & Low $(<0.05)$ & $\begin{array}{c}\text { Moderately reduced } \\
\quad(0.05-0.19)\end{array}$ & Normal (0.20-4.00) & $\begin{array}{c}\text { Moderately elevated } \\
\quad(4.01-5.00)\end{array}$ & High $(\geq 5.00)$ \\
\hline \multicolumn{6}{|c|}{ Total VTE $(n=289)$} \\
\hline Person-years & 390 & 869 & 91429 & 2699 & 2285 \\
\hline Events & 3 & 2 & 259 & 13 & 12 \\
\hline$I^{a}$ & $7.70(2.48-23.9)$ & $2.30(0.58-9.20)$ & $2.83(2.51-3.20)$ & $4.82(2.80-8.29)$ & $5.25(2.98-9.25)$ \\
\hline$H R^{b}$ & $2.30(0.73-7.18)$ & $0.71(0.18-2.84)$ & 1.00 (ref.) & $1.29(0.74-2.25)$ & $1.46(0.82-2.61)$ \\
\hline $\mathrm{HR}^{\mathrm{c}}$ & $2.16(0.69-6.76)$ & $0.73(0.18-2.95)$ & 1.00 (ref.) & $1.32(0.75-2.31)$ & $1.55(0.87-2.77)$ \\
\hline \multicolumn{6}{|c|}{ Provoked VTE $(n=175)$} \\
\hline Person-years & 390 & 869 & 91429 & 2699 & 2285 \\
\hline Events & 2 & 1 & 154 & 9 & 9 \\
\hline$I^{a}$ & $5.13(0.13-20.53)$ & $1.15(0.16-8.17)$ & $1.68(1.44-1.97)$ & $3.33(1.73-6.41)$ & $3.94(2.05-7.57)$ \\
\hline $\mathrm{HR}^{\mathrm{b}}$ & $2.68(0.66-10.85)$ & $0.60(0.84-4.32)$ & 1.00 (ref.) & $1.51(0.77-2.97)$ & $1.87(0.95-3.66)$ \\
\hline$H R^{c}$ & $2.51(0.62-10.19)$ & $0.63(0.09-4.53)$ & 1.00 (ref.) & $1.59(0.81-3.13)$ & $1.99(1.01-3.90)$ \\
\hline \multicolumn{6}{|c|}{ Unprovoked VTE $(n=114)$} \\
\hline Person-years & 390 & 869 & 91429 & 2699 & 2285 \\
\hline Events & 1 & 1 & 105 & 4 & 3 \\
\hline$I^{a}$ & $2.57(0.36-18.22)$ & $1.15(0.16-8.17)$ & $1.15(0.95-1.39)$ & $1.48(0.56-3.95)$ & $1.31(0.42-4.07)$ \\
\hline $\mathrm{HR}^{\mathrm{b}}$ & $1.78(0.25-12.77)$ & $0.85(0.12-6.13)$ & 1.00 (ref.) & $0.96(0.35-2.61)$ & $0.88(0.28-2.79)$ \\
\hline $\mathrm{HR}^{\mathrm{C}}$ & $1.66(0.23-11.99)$ & $0.87(0.12-6.23)$ & 1.00 (ref.) & $0.95(0.35-2.60)$ & $0.94(0.30-2.97)$ \\
\hline \multicolumn{6}{|l|}{ DVT $(n=164)$} \\
\hline Person-years & 390 & 869 & 91429 & 2699 & 2285 \\
\hline Events & 2 & 1 & 146 & 8 & 7 \\
\hline$I^{a}$ & $5.13(1.28-20.5)$ & $1.15(0.16-8.17)$ & $1.60(1.36-1.88)$ & $2.96(1.48-5.93)$ & $3.06(1.46-6.43)$ \\
\hline $\mathrm{HR}^{\mathrm{b}}$ & $2.75(0.68-11.1)$ & $0.62(0.09-4.43)$ & 1.00 (ref.) & $1.49(0.73-3.04)$ & $1.58(0.74-3.38)$ \\
\hline $\mathrm{HR}^{\mathrm{c}}$ & $2.72(0.67-11.0)$ & $0.66(0.09-4.74)$ & 1.00 (ref.) & $1.58(0.77-3.22)$ & $1.70(0.80-3.65)$ \\
\hline \multicolumn{6}{|l|}{$\operatorname{PE}(n=125)$} \\
\hline Person-years & 390 & 869 & 91429 & 2699 & 2285 \\
\hline Events & 1 & 1 & 113 & 5 & 5 \\
\hline$I R^{a}$ & $2.57(0.36-18.2)$ & $1.15(0.16-8.17)$ & $1.24(1.03-1.49)$ & $1.85(0.77-4.45)$ & $2.19(0.91-5.26)$ \\
\hline $\mathrm{HR}^{\mathrm{b}}$ & $1.74(0.24-12.5)$ & $0.83(0.11-5.93)$ & 1.00 (ref.) & $1.05(0.43-2.58)$ & $1.32(0.54-3.24)$ \\
\hline $\mathrm{HR}^{\mathrm{c}}$ & $1.52(0.21-11.0)$ & $0.83(0.11-5.94)$ & 1.00 (ref.) & $1.04(0.42-2.56)$ & $1.37(0.56-3.37)$ \\
\hline
\end{tabular}

\section{Discussion}

We found no clear association between TSH levels and risk of VTE at the population level. However, subjects with low and high TSH had slightly higher risk estimates as compared to subjects with normal TSH. The risk estimates by both high and low TSH were augmented for provoked VTE and DVT. A higher risk of provoked VTE may suggest that thyroid dysfunction (i.e., both high and low TSH) predispose for VTE through associated hospitalization or comorbidities. The present results should be interpreted with caution because of the low number of events in subjects with thyroid dysfunction. At the same time, the low prevalence of thyroid dysfunction in our general population suggests that only a minor proportion of the VTEs in the population can be attributed to thyroid dysfunction.
Previous data concerning the impact of thyroid function on VTE risk are scarce. A registry-based study (7) of 19519000 subjects showed no relationship between hyperthyroidism and VTE, although a 1.6-fold increased risk of VTE was reported in hypothyroid patients identified by diagnosis codes. Unfortunately, no information on the time between the VTE event and the diagnosis of thyroid dysfunction was given, and no data was available on the degree of thyroid dysfunction and important confounders, such as BMI. In contrast, a case-control study (21) of 155 DVT cases and 379 sex-matched controls reported a 1.7- to 5.7-fold higher risk of DVT in the upper 60th-99th percentiles of $\mathrm{FT}_{4}$ levels within the local reference range (10-24 pmol/1). In addition, a nested case-cohort study (22) of 446 VTE cases and 1228 age- and sex-matched controls reported a 1.5 - to 2.5 -fold higher risk of VTE in 


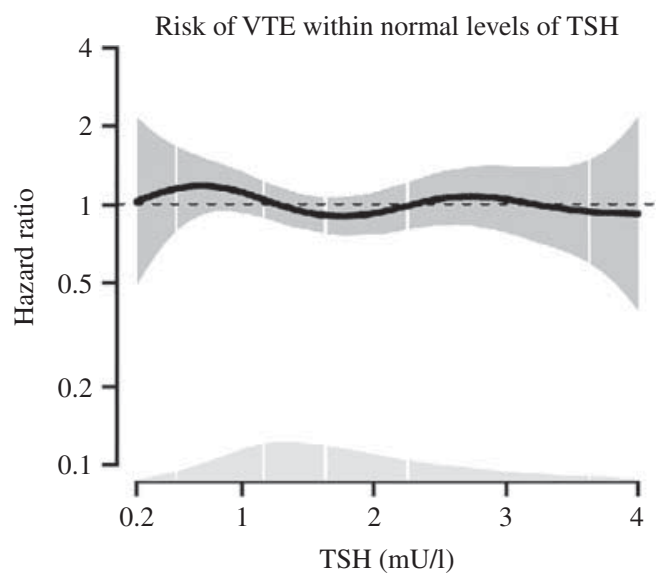

Figure 2

Dose-response relationship between thyroid-stimulating hormone (TSH) in the normal reference range and risk of venous thromboembolism (VTE) obtained by generalized linear regression. The regression model is adjusted for age, sex, BMI, and smoking. The solid line shows hazard ratios (HRs), and the shaded area shows $95 \% \mathrm{Cls}$. Density plots show the distribution of TSH, and white vertical lines indicate the 2.5th, 25th, 50th, 75th, and 97.5th percentiles.

the higher 90th-98th percentiles of $\mathrm{FT}_{4}$ levels within the local reference range (9-19 pmol/l). None of these studies observed a clear association between TSH and VTE. A nonsignificant $\mathrm{OR}$ of 1.3 was observed in the lower 2 nd percentile $(<0.37 \mathrm{mU} / 1 \mathrm{TSH})$ in the nested case-cohort study (22). These findings are supported by experimental studies $(30,31)$ that reported that high TSH levels with normal $\mathrm{FT}_{4}$ have no influence on hemostatic parameters and that the effect on the coagulation system is mainly mediated by $\mathrm{FT}_{4}$.

The retrospective nature of case-control studies results in an indecisive sequence of exposure and outcome, and therefore it cannot be definitely established whether the associated variable is a response to, rather than a cause of, the disease. Moreover, if selection bias occurs during control sampling, the exposure distribution in the control population may not reflect the true exposure in the source population. Thus, the reported risk of VTE by increased levels of $\mathrm{FT}_{4}$ in a previous case-control study (21) may potentially be overestimated. In a prospective cohort study, an underestimation of the true association is more likely to have occurred as the result of a regression dilution effect (i.e., intra-individual changes in TSH during longterm follow-up could bias the risk estimates toward the null). To minimize the regression dilution effect in the present study, we performed a time-varying analysis, which allowed for changes in TSH over time in subjects who were measured more than once during follow-up.

In the present study, the apparently U-shaped association between TSH levels and risk of VTE supports previous findings that link both hyperthyroidism and subclinical and overt hypothyroidism to a hypercoagulable state $(3,4,5,6,7,8,9,10)$. Previous case-control and case-cohort studies $(21,22)$ have shown that there is a particular association between elevated levels of $\mathrm{FT}_{4}$ and a risk of VTE. Accordingly, we observed a twofold higher risk of VTE in subjects with low TSH as compared to subjects with normal TSH. However, our findings may also suggest that factors other than thyroid hormones alone contribute to the risk of VTE in subjects with hyper- and hypothyroidism. This notion is further supported by the observed association between thyroid dysfunction and provoked VTE. Hence, the link between thyroid dysfunction and VTE may be mediated by provoking factors, such as arterial cardiovascular events or immobilization, which further predispose for VTE.

Experimental studies have shown associations between thyroid disease and a concentration of coagulation factors $(30,31,32,33,34,35)$. Recently, levothyroxine substitution in thyroid carcinoma patients treated with total thyroidectomy resulted in a rise in $\mathrm{FT}_{4}$ from almost zero to slightly above the normal range, accompanied by a significant increase in plasma levels of FVIII and VWF (31). Contrarily, recombinant human TSH supplementation in thyroid carcinoma patients treated with total thyroidectomy caused increased TSH levels with only minor effect on $\mathrm{FT}_{4}$ levels and no effect on the coagulation factors. Even though there is a stringent inverse relation between TSH and $\mathrm{FT}_{4}$ under physiological conditions, the latter findings may to some extent support a stronger relationship between $\mathrm{FT}_{4}$ and VTE risk than that between TSH and VTE risk under dysfunctional conditions.

We found no clear evidence for an association between either low or high levels of TSH and a risk of VTE in the general population. The calculated PAR\% of thyroid dysfunction for VTE in the present study suggests that thyroid dysfunction accounts for $4 \%$ of the VTE events in the population, which indicates that thyroid dysfunction has no substantial public health implications with regard to VTE risk.

Overall, the present study provided $80 \%$ statistical power for assessing an HR of 1.12 for VTE by the continuous TSH variable. However, because of the low number of subjects with low TSH $(n=41)$, we only had $5 \%$ statistical power to detect a 2.16 -fold increased risk of 
VTE in subjects within the lowest category of TSH $(<0.05 \mathrm{mU} / \mathrm{ml})$. Consequently, there was a 95\% probability of type 2 error. With a population prevalence of low TSH of $0.2 \%$, we would have needed a cohort of $\sim 550000$ subjects to detect an HR of 2.0 with $80 \%$ statistical power. It is likely to assume that subjects with low TSH $(<0.05 \mathrm{mU} / \mathrm{ml})$ are detected and treated at an early stage of the disease, because overt hyperthyroidism often has classical troublesome symptoms. This may be a source of regression dilution effect, seeing as the treatment of overt hyperthyroidism modifies the levels of TSH.

The main strengths of the present study are its large number of participants and validated VTE events, its prospective design, and its long-term follow-up. We used a time-varying analysis that allowed for changes in TSH over time. The use of time-varying analysis is especially important when dealing with modifiable risk factors and when time between exposure assessment and disease manifestation is long. The issue of statistical power is of critical importance for the proper interpretation of risk estimates, but in the present study, a low prevalence of subjects with low and high TSH levels led to limited statistical power for risk assessment in these groups, which resulted in wide CIs. Unfortunately, $\mathrm{FT}_{4}$ was not measured in the Tromsø study, and the potential impact of $\mathrm{FT}_{4}$ on the risk of VTE could therefore not be explored.

In the present population-based cohort study, levels of TSH within the normal range were not associated with a future risk of VTE. However, there was a tendency of increased VTE risk among subjects with high and low TSH levels, but the results should be interpreted with caution because of the low statistical power in these categories. Nevertheless, the low prevalence of thyroid dysfunction and the correspondingly low PAR\% suggest that the low proportion of VTE events in the general population can be attributed to thyroid dysfunction.

\section{Declaration of interest}

The authors declare that there is no conflict of interest that could be perceived as prejudicing the impartiality of the research reported.

\section{Funding}

K.G. Jebsen Thrombosis Research and Expertise Center (TREC) was supported by an independent grant from the K.G. Jebsen Foundation.

\section{Author contribution statement}

G Lerstad and K F Enga carried out the statistical analysis. G Lerstad and E E Brodin interpreted the results and drafted the manuscript. S K Brækkan and J-B Hansen designed the study, collected the data, and critically revised the manuscript. G Lerstad and S K Brækkan full access to the data and take full responsibility for its integrity and the accuracy of the data analysis.

\section{References}

1 Wang C \& Crapo LM. The epidemiology of thyroid disease and implications for screening. Endocrinology and Metabolism Clinics of North America 199726 189-218. (doi:10.1016/S0889-8529(05)70240-1)

2 Bjoro T, Holmen J, Kruger O, Midthjell K, Hunstad K, Schreiner T, Sandnes L \& Brochmann H. Prevalence of thyroid disease, thyroid dysfunction and thyroid peroxidase antibodies in a large, unselected population. The Health Study of Nord-Trondelag (HUNT). European Journal of Endocrinology 2000143 639-647. (doi:10.1530/eje.0.1430639)

3 Franchini M. Hemostatic changes in thyroid diseases: haemostasis and thrombosis. Hematology 200611 203-208. (doi:10.1080/ 10245330600667591)

4 Erem C, Ersoz HO, Karti SS, Ukinc K, Hacihasanoglu A, Deger O \& Telatar M. Blood coagulation and fibrinolysis in patients with hyperthyroidism. Journal of Endocrinological Investigation 200225 345-350. (doi:10.1007/BF03344016)

5 Marongiu F, Conti M, Murtas ML, Mameli G, Sorano GG \& Martino E. Activation of blood coagulation and fibrinolysis in Graves' disease. Hormone and Metabolic Research 199123 609-611. (doi:10.1055/s-20071003766)

6 Erem C. Blood coagulation, fibrinolytic activity and lipid profile in subclinical thyroid disease: subclinical hyperthyroidism increases plasma factor X activity. Clinical Endocrinology 200664 323-329. (doi:10.1111/j.1365-2265.2006.02464.x)

7 Danescu LG, Badshah A, Danescu SC, Janjua M, Marandici AM, Matta F, Yaekoub AY, Malloy DJ \& Stein PD. Venous thromboembolism in patients hospitalized with thyroid dysfunction. Clinical and Applied Thrombosis/ Hemostasis 200915 676-680. (doi:10.1177/1076029609336856)

8 Chadarevian R, Bruckert E, Ankri A, Beucler I, Giral P \& Turpin G. Relationship between thyroid hormones and plasma D-dimer levels. Thrombosis and Haemostasis 199879 99-103.

9 Marongiu F, Biondi G, Conti M, Murtas ML, Mameli G, Sorano GG \& Martino E. Is a hypercoagulable state present in hypothyroidism? Thrombosis and Haemostasis 199267729.

10 Erem C, Kavgaci H, Ersoz HO, Hacihasanoglu A, Ukinc K, Karti SS, Deger $\mathrm{O} \&$ Telatari M. Blood coagulation and fibrinolytic activity in hypothyroidism. International Journal of Clinical Practice 200357 78-81.

11 Nyirenda MJ, Clark DN, Finlayson AR, Read J, Elders A, Bain M, Fox KA $\&$ Toft AD. Thyroid disease and increased cardiovascular risk. Thyroid 200515 718-724. (doi:10.1089/thy.2005.15.718)

12 Parle JV, Maisonneuve P, Sheppard MC, Boyle P \& Franklyn JA. Prediction of all-cause and cardiovascular mortality in elderly people from one low serum thyrotropin result: a 10-year cohort study. Lancet 2001358 861-865. (doi:10.1016/S0140-6736(01)06067-6)

13 Glynn RJ \& Rosner B. Comparison of risk factors for the competing risks of coronary heart disease, stroke, and venous thromboembolism. American Journal of Epidemiology 2005162 975-982. (doi:10.1093/aje/ kwi309)

14 Heit JA. Venous thromboembolism: disease burden, outcomes and risk factors. Journal of Thrombosis and Haemostasis 20053 1611-1617. (doi:10.1111/j.1538-7836.2005.01415.x)

15 Silverstein MD, Heit JA, Mohr DN, Petterson TM, O'Fallon WM \& Melton LJ III. Trends in the incidence of deep vein thrombosis and pulmonary embolism: a 25-year population-based study. Archives of Internal Medicine 1998158 585-593. (doi:10.1001/archinte.158.6.585)

16 Robetorye RS \& Rodgers GM. Update on selected inherited venous thrombotic disorders. American Journal of Hematology 200168 256-268. (doi:10.1002/ajh.10002) 
17 Rosendaal FR. Venous thrombosis: a multicausal disease. Lancet 1999 353 1167-1173. (doi:10.1016/S0140-6736(98)10266-0)

18 Cushman M, Tsai AW, White RH, Heckbert SR, Rosamond WD, Enright P \& Folsom AR. Deep vein thrombosis and pulmonary embolism in two cohorts: the longitudinal investigation of thromboembolism etiology. American Journal of Medicine 2004117 19-25. (doi:10.1016/j.amjmed.2004.01.018)

19 Prandoni P, Bilora F, Marchiori A, Bernardi E, Petrobelli F, Lensing AW, Prins $\mathrm{MH} \&$ \& Girolami A. An association between atherosclerosis and venous thrombosis. New England Journal of Medicine $2003 \mathbf{3 4 8}$ 1435-1441. (doi:10.1056/NEJMoa022157)

20 White RH. The epidemiology of venous thromboembolism. Circulation 2003 107 I4-I8. (doi:10.1161/01.CIR.0000078468.11849.66)

21 van Zaane B, Squizzato A, Huijgen R, van Zanten AP, Fliers E, Cannegieter SC, Buller HR, Gerdes VE \& Brandjes DP. Increasing levels of free thyroxine as a risk factor for a first venous thrombosis: a case-control study. Blood 2010115 4344-4349. (doi:10.1182/blood-2009-11-253724)

22 Debeij J, Dekkers OM, Asvold BO, Christiansen SC, Naess IA, Hammerstrom J, Rosendaal FR \& Cannegieter SC. Increased levels of free thyroxine and risk of venous thrombosis in a large populationbased prospective study. Journal of Thrombosis and Haemostasis $2012 \mathbf{1 0}$ 1539-1546. (doi:10.1111/j.1538-7836.2012.04818.x)

23 Jacobsen BK, Eggen AE, Mathiesen EB, Wilsgaard T \& Njolstad I. Cohort profile: the Tromso study. International Journal of Epidemiology 201241 961-967. (doi:10.1093/ije/dyr049)

24 Borch KH, Braekkan SK, Mathiesen EB, Njolstad I, Wilsgaard T, Stormer J \& Hansen JB. Abdominal obesity is essential for the risk of venous thromboembolism in the metabolic syndrome: the Tromso study. Journal of Thrombosis and Haemostasis 20097 739-745. (doi:10.1111/j.1538-7836.2008.03234.x)

25 Braekkan SK, Mathiesen EB, Njolstad I, Wilsgaard T, Stormer J \& Hansen JB. Mean platelet volume is a risk factor for venous thromboembolism: the Tromso study, Tromso, Norway. Journal of Thrombosis and Haemostasis 20108 157-162. (doi:10.1111/j.1538-7836.2009.03498.x)

26 Schmidt M, Horvath-Puho E, Thomsen RW, Smeeth L \& Sorensen HT. Acute infections and venous thromboembolism. Journal of Internal Medicine 2012271 608-618. (doi:10.1111/j.1365-2796.2011.02473.x)
27 Ageno W, Becattini C, Brighton T, Selby R \& Kamphuisen PW. Cardiovascular risk factors and venous thromboembolism: a metaanalysis. Circulation 2008117 93-102. (doi:10.1161/CIRCULATIONAHA.107.709204)

28 Lohiya GS, Tan-Figueroa L, Silverman S \& Van Le H. The wheelchair thrombosis syndrome. Journal of the National Medical Association 2006 98 1188-1192.

29 Arpaia G, Bavera PM, Caputo D, Mendozzi L, Cavarretta R, Agus GB, Milani M, Ippolito E \& Cimminiello C. Risk of deep venous thrombosis (DVT) in bedridden or wheelchair-bound multiple sclerosis patients: a prospective study. Thrombosis Research 2010125 315-317. (doi:10.1016/j.thromres.2009.06.023)

30 Yango J, Alexopoulou O, Eeckhoudt S, Hermans C \& Daumerie C. Evaluation of the respective influence of thyroid hormones and TSH on blood coagulation parameters after total thyroidectomy. European Journal of Endocrinology 2011164 599-603. (doi:10.1530/EJE-10-0837)

31 Debeij J, Cannegieter SC, VAN Zaane B, Smit JW, Corssmit EP, Rosendaal FR, Romijn JA \& Dekkers OM. The effect of changes in thyroxine and thyroid-stimulating hormone levels on the coagulation system. Journal of Thrombosis and Haemostasis 20108 2823-2826. (doi:10.1111/j.1538-7836.2010.04054.x)

32 Squizzato A, Romualdi E, Buller HR \& Gerdes VE. Clinical review: Thyroid dysfunction and effects on coagulation and fibrinolysis: a systematic review. Journal of Clinical Endocrinology and Metabolism 200792 2415-2420. (doi:10.1210/jc.2007-0199)

33 Hofbauer LC \& Heufelder AE. Coagulation disorders in thyroid diseases. European Journal of Endocrinology 1997136 1-7. (doi:10.1530/ eje.0.1360001)

34 Gullu S, Sav H \& Kamel N. Effects of levothyroxine treatment on biochemical and hemostasis parameters in patients with hypothyroidism. European Journal of Endocrinology 2005152 355-361. (doi:10.1530/eje.1.01857)

35 Michiels JJ, Schroyens W, Berneman Z \& van der Planken M. Acquired von Willebrand syndrome type 1 in hypothyroidism: reversal after treatment with thyroxine. Clinical and Applied Thrombosis/Hemostasis 20017 113-115. (doi:10.1177/107602960100700206)

Received 17 February 2015

Revised version received 13 April 2015

Accepted 20 April 2015 